\title{
C-reactive protein for prediction of atrial fibrillation recurrence after catheter ablation
}

Pascal B. Meyre ${ }^{1,2^{*}}$ (D), Christian Sticherling ${ }^{1,2}$, Florian Spies ${ }^{1,2}$, Stefanie Aeschbacher ${ }^{1,2}$, Steffen Blum ${ }^{1,2}$, Gian Voellmin ${ }^{1,2}$, Antonio Madaffari ${ }^{1,2}$, David Conen ${ }^{1,3}$, Stefan Osswald ${ }^{1,2}$, Michael Kühne ${ }^{1,2+}$ and Sven Knecht ${ }^{1,2+}$

\begin{abstract}
Background: Inflammation plays an important role in the initiation and progression of atrial fibrillation (AF), but data about the relationship between subclinical inflammation and recurrence of AF after catheter ablation remains poorly studied. We aimed to assess whether plasma levels of C-reactive protein (CRP) are associated with long-term AF recurrence following catheter ablation.

Methods: Prior to the intervention, plasma CRP concentrations were measured in patients who underwent first catheter ablation for AF. AF recurrence was evaluated after 12 months and defined as any AF episode longer than $30 \mathrm{~s}$ recorded on either 12-lead electrocardiogram, 24-h Holter or 7-day Holter monitoring. Multivariable adjusted Cox models were constructed to examine the association of CRP levels and AF recurrence.

Results: Of the 711 patients (mean age: 61 years, 25\% women) included in this study, 247 patients (35\%) experienced AF recurrence after ablation. Patients who were in the highest CRP quartile had a higher rate of recurrent AF compared to those who were in the lowest quartile $(53.4$ vs. 33.1\% at 1 year of follow-up; $P=0.004$ ). The adjusted hazard ratios (aHR) of recurrent AF across increasing quartiles of CRP were 1.0 (reference), 1.26 (95\% confidence interval $[\mathrm{Cl}], 0.86-1.84), 1.15(95 \% \mathrm{Cl}, 0.78-1.70)$ and $1.60(95 \% \mathrm{Cl}, 1.10-2.34)(\mathrm{P}$ trend $=0.015)$. A similar effect was observed when CRP was analyzed as continuous variable (aHR per unit increase, 1.21; 95\% Cl, 1.05-1.39; $P=0.009$ ). When a predefined CRP cut-off of $3 \mathrm{mg} / \mathrm{l}$ was applied, patients with CRP levels of $3 \mathrm{mg} / \mathrm{l}$ or above had a higher risk of $\mathrm{AF}$ recurrence than those with levels below (aHR, 1.44; 95\% $\mathrm{Cl}, 1.06-1.95 ; P=0.019$ ).
\end{abstract}

Conclusions: Increasing pre-interventional CRP levels are associated with a higher risk of AF recurrence in patients undergoing catheter ablation for AF.

Trail registration: ClinicalTrials.gov identifier, NCT03718364.

Keywords: Atrial fibrillation, Catheter ablation, C-reactive protein, Recurrence

\footnotetext{
* Correspondence: pascal.meyre@usb.ch

${ }^{\dagger}$ Michael Kühne and Sven Knecht contributed equally, shared last authors

'Division of Cardiology, Department of Medicine, University Hospital Basel, Petersgraben 4, 4031 Basel, Switzerland

${ }^{2}$ Cardiovascular Research Institute Basel, University Hospital Basel, Basel, Switzerland

Full list of author information is available at the end of the article
}

C C The Author(s). 2020 Open Access This article is licensed under a Creative Commons Attribution 4.0 International License, which permits use, sharing, adaptation, distribution and reproduction in any medium or format, as long as you give appropriate credit to the original author(s) and the source, provide a link to the Creative Commons licence, and indicate if changes were made. The images or other third party material in this article are included in the article's Creative Commons licence, unless indicated otherwise in a credit line to the material. If material is not included in the article's Creative Commons licence and your intended use is not permitted by statutory regulation or exceeds the permitted use, you will need to obtain permission directly from the copyright holder. To view a copy of this licence, visit http://creativecommons.org/licenses/by/4.0/. The Creative Commons Public Domain Dedication waiver (http://creativecommons.org/publicdomain/zero/1.0/) applies to the data made available in this article, unless otherwise stated in a credit line to the data. 


\section{Background}

Atrial fibrillation (AF) currently affects more than 18 million Europeans and its prevalence is increasing rapidly $[1,2]$. Patients with AF face a high risk of stroke, heart failure and death [3, 4]. Catheter ablation has become a well-established option for antiarrhythmic drug refractory AF, and it is accepted as first-line therapy in patients with symptomatic paroxysmal AF [5-7]. However, the rates of AF recurrence after an initially successful catheter ablation are high, with estimates ranging from 24 to $50 \%$ within the first months [8-10].

Epidemiologic and histological evidence suggests that inflammation may play an important role in the initiation and maintenance of AF $[11,12]$. In the Women's Health Study, elevated levels of pro-inflammatory biomarkers measured at baseline were associated with a higher risk of new-onset AF [13]. This and other studies showed that elevated levels of C-reactive protein (CRP), which is a well-known marker for local and systemic inflammation, are independently associated with an increased risk of incident AF [13-17]. Elevated baseline CRP levels predict AF recurrence following a successful electrical cardioversion [18], but the role of inflammation in the risk of AF recurrence after catheter ablation is less well-defined. Smaller and older studies with partially outdated interventional strategies showed inconsistent results [19-22]. Systemic inflammation may induce an electrical and mechanical substrate that then promotes AF episodes and increases the susceptibility for recurrent AF after ablation [11]. We therefore aimed to evaluate the association of elevated levels of CRP measured prior to catheter ablation with AF recurrence during a follow-up of 12 months.

\section{Methods}

\section{Study design and population}

The study population was derived from the Swiss Atrial Fibrillation Pulmonary Vein Isolation (SWISS-AF PVI) study, an ongoing prospective cohort study in Switzerland enrolling patients $>18$ years of age with diagnosed AF who are scheduled to undergo first elective catheter ablation. Exclusion criteria were presence of longstanding persistent or permanent AF, and inability or unwillingness to participate in the study. Also, patients were excluded if they were experiencing acute inflammatory conditions (such as pneumonia or urosepsis) or showed symptoms of acute illness at baseline. However, this group of patients was eligible for enrolment 4 weeks after stabilization of their acute episode. None of the patients had diagnosed rheumatoid arthritis at baseline. The study protocol was approved by the local ethics committee, and written informed consent was obtained from all participants.

\section{Study procedures}

Data on personal and medical characteristics were collected at baseline by study personnel using standardized case report forms. Information on demographics, lifestyle habits, medical history, and current medications was obtained. Prior to the ablation procedure, we performed transthoracic echocardiography to quantify left atrial dimension and left ventricular ejection fraction (LVEF). Type of AF was classified according to the current guidelines either as paroxysmal (self-terminating $\mathrm{AF}$, within $48 \mathrm{~h}$ ) or persistent AF (episodes lasting longer than 7 days, including episodes terminated by cardioversion after 7 days or more) [23].

\section{Blood sampling}

Venous blood samples were obtained and processed at the day prior to ablation. Plasma levels of CRP were measured using an immunoturbidimetry on latex assay (C-Reactive Protein Gen.3, Roche Diagnostics). This assay allows quantification of CRP plasma levels below $2 \mathrm{mg} / \mathrm{L}$ (detection range of 0.3 to $350 \mathrm{mg} / \mathrm{L}$ ), which is sufficient for cardiovascular risk assessment [24-26].

\section{Catheter ablation}

Catheter ablation procedures aimed to restore sinus rhythm through isolation of all pulmonary veins. Ablation strategy and mapping system selection was left to the discretion of the electrophysiologist. Only experienced electrophysiologists who have had performed several AF ablation procedures, including pulmonary vein isolation, using the same approach were allowed to perform the ablation procedures. At the discretion of the operators, additional lesions were placed. The operators were unaware of the patients measured CRP levels.

\section{Follow-up and outcome}

Regular follow-up visits in outpatient clinics were conducted by physicians at 3,6 , and 12 months. At each visit, a detailed medical and physical examination, 12lead electrocardiogram, 24-h Holter, and 7-day Holter monitoring at 12 months were performed. In some patients the 7-day Holter was performed beyond the scheduled 12-month visit. All recordings were centrally collected at the University Hospital Basel and outcomes were adjudicated by trained study personnel and cardiologists. The outcome was AF recurrence defined as any AF or atrial tachycardia episode lasting longer than $30 \mathrm{~s}$, which is in accordance with the 2017 Heart Rhythm Society expert consensus statement [27].

\section{Statistical analysis}

A blanking period was applied to exclude events that occurred during the first 90 days after ablation, as recommended by the current guidelines [27]. Baseline 
characteristics were stratified according to quartiles of CRP levels. Continuous variables are described as mean \pm standard deviation or as median and interquartile range (IQR) and categorical variables are presented as counts (percentages) and compared using tests for linear trend across CRP quartiles.

We used a multistage process to address the effect of CRP levels on the rates of AF recurrence that occurred after the blanking period. First, we divided patients into quartiles of CRP levels; the lowest quartile was defined as the reference. Incidence rates stratified by CRP quartiles were calculated at 1 year of follow-up and compared using the trend test for survival functions. Kaplan-Meier survival curves were used to estimate the cumulative incidence of recurrent AF across CRP quartiles and compared using log-rank test. We constructed Cox proportional hazard models to assess the risk of AF recurrence across CRP quartiles. The first model was unadjusted, the second model was adjusted for age and sex, and the third model was adjusted for age, sex, body mass index, AF type (paroxysmal vs. persistent), history of hypertension (yes vs. no), history of heart failure (yes vs. no), history of obstructive sleep apnea (yes vs. no), AF duration in years, and left atrial diameter (LAD). Second, we log-transformed CRP levels and repeated the analysis process using CRP as a continuous variable. Multivariable models were adjusted for the same set of variables as described above.

In additional analyses, we stratified the study population at a CRP cut-off value of $3 \mathrm{mg} / \mathrm{l}$, a level known to be associated with high cardiovascular risk [28-30]. We evaluated whether the rates of AF recurrence differed in patients below or above this value and constructed the same multivariable models as described above.

All analyses were performed using Stata, version 13 (StataCorp. 2013. College Station, TX: StataCorp LP) and a two-sided $P$-value $<0.05$ was considered to indicate statistical significance.

\section{Results}

From April 29, 2010, through May 11, 2017, we enrolled 847 AF patients in the study. Of those, 748 patients completed at least one follow-up visit (Figure S1 in the Supplement). We excluded 37 patients due to missing CRP values at baseline $(n=33)$ and because blood samples were drawn after catheter ablation $(n=4)$. The median follow-up duration was 1.0 years (IQR, 0.5-1.2). Of the $711 \mathrm{AF}$ patients included in our analyses, 247 (35\%) experienced AF recurrence after ablation. Table 1 shows baseline characteristics of patients by quartiles of CRP levels. Significant differences were observed for age, sex, body-mass index, AF type, LAD and LVEF in the baseline echocardiogram, white blood cell count, for the frequency of hypertension and heart failure as well as for the history of amiodarone treatment across CRP categories.

Table 2 presents the number of events and AF recurrence rates stratified by CRP quartiles. Incidence rates of AF recurrence for those in the second $(0.8-1.4 \mathrm{mg} / \mathrm{l})$, third $(1.5-2.7 \mathrm{mg} / \mathrm{l})$ and highest quartiles of CRP $(>2.7$ $\mathrm{mg} / \mathrm{l})$ were higher as compared to those in the lowest quartile $(<0.8 \mathrm{mg} / \mathrm{l})$. A threshold effect was observed between quartiles of CRP and AF recurrence, whereas the incidence rate was highest in the highest quartile ( $\mathrm{P}$ for trend across quartiles $=0.017$ ). Figure 1 shows the cumulative incidence of recurrent AF according to CRP quartiles after the blanking period $(\log$-rank $P=0.04)$. In the fully adjusted model, the hazard ratios (aHR) for those in the second, third and highest quartiles of CRP, as compared to those in the in lowest quartile (reference), were 1.26 (95\% confidence interval [CI], 0.861.84; $P=0.24$ ), 1.15 (95\% CI, 0.78-1.70; $P=0.48$ ), and 1.60 (95\% CI, 1.10-2.34; $P=0.014$ ), respectively (Table 3 ). Data on CRP analyzed as continuous variable are shown in Table 3. A per unit increase in log CRP was associated with an aHR of 1.21 (95\% CI, 1.05-1.39; $P=0.009)$.

Patients who had CRP levels above the cut-off of 3 $\mathrm{mg} / \mathrm{l}$ had higher rates of recurrent AF than patients with levels below $3 \mathrm{mg} / \mathrm{l}$ (66 patients [41\%] vs. 181 patients [33\%]; log-rank $P=0.009$ ) (Table 4). Kaplan-Meier curves are shown in the Fig. 2. In multivariable analysis, the risk of AF recurrence was higher in patients who had CRP levels above $3 \mathrm{mg} / \mathrm{l}$, as compared to those with levels below the cut-off value (aHR, 1.44; 95\% CI, 1.061.95; $P=0.019)$ (Table 4).

\section{Discussion}

In this comprehensive analysis of AF patients who underwent first catheter ablation, increasing preinterventional plasma levels of CRP were associated with a higher risk of AF recurrence. Patients in the highest CRP quartile had a $60 \%$ higher risk of recurrent AF compared to those who were in the lowest CRP quartile after adjustment for known risk factors for recurrence. These results were consistent when CRP levels were analyzed as a continuous variable or with a cut-off at $3 \mathrm{mg} /$ 1 , suggesting that our findings are robust and not dependent on specific cut-off values. Adjusting for a broad set of potential confounders had little effect on the risk estimates, suggesting that residual confounding is less likely.

Although it is well-established that inflammation is independently associated with the development of AF [13-15], much less is known about whether inflammation increases the risk for $\mathrm{AF}$ recurrence after catheter ablation. Markers of inflammation including fibrosis, leukocyte infiltrates and oxidative damage have been found in atrial tissue samples of subjects with AF [12, 
Table 1 Baseline characteristics according to CRP level groups

\begin{tabular}{|c|c|c|c|c|c|}
\hline \multirow[b]{2}{*}{ Characteristic } & \multicolumn{4}{|l|}{ CRP Level } & \multirow[b]{2}{*}{$P$ trend } \\
\hline & $\begin{array}{l}\text { Quartile } 1 \\
(N=201)\end{array}$ & $\begin{array}{l}\text { Quartile } 2 \\
(N=171) \\
\end{array}$ & $\begin{array}{l}\text { Quartile } 3 \\
(N=167) \\
\end{array}$ & $\begin{array}{l}\text { Quartile } 4 \\
(N=172)\end{array}$ & \\
\hline Age, years & $59.1 \pm 10.7$ & $60.1 \pm 8.8$ & $61.5 \pm 8.8$ & $61.6 \pm 9.5$ & 0.016 \\
\hline Female sex & $42(21)$ & $36(21)$ & $45(27)$ & $50(30)$ & 0.019 \\
\hline Body mass index, $\mathrm{kg} / \mathrm{m}^{2}$ & $25.4 \pm 3.9$ & $27.4 \pm 4.0$ & $27.7 \pm 4.3$ & $29.2 \pm 6.1$ & $<0.001$ \\
\hline Systolic blood pressure, $\mathrm{mm} \mathrm{Hg}$ & $135 \pm 17$ & $135 \pm 18$ & $135 \pm 18$ & $136 \pm 20$ & 0.78 \\
\hline Type of atrial fibrillation & & & & & $<0.001$ \\
\hline Paroxysmal & $139(70)$ & $108(63)$ & $97(58)$ & $90(52)$ & \\
\hline Persistent & $61(30)$ & $63(37)$ & $69(42)$ & $82(48)$ & \\
\hline Atrial fibrillation duration, years & $2.3(0.6-6.6)$ & $1.7(0.5-4.8)$ & $2.2(0.6-6.1)$ & $2.0(0.6-5.6)$ & 0.72 \\
\hline \multicolumn{6}{|l|}{ Echocardiographic parameters } \\
\hline$L A D, m m$ & $39 \pm 7$ & $42 \pm 7$ & $42 \pm 7$ & $43 \pm 6$ & $<0.001$ \\
\hline LVEF, \% & $58 \pm 10$ & $57 \pm 9$ & $57 \pm 10$ & $55 \pm 12$ & $<0.001$ \\
\hline \multicolumn{6}{|l|}{ Laboratory data } \\
\hline $\mathrm{WBC}, \mathrm{mm}^{3}$ & $5860(5020-6840)$ & $6135(5135-7515)$ & $6440(5290-7820)$ & $6900(5740-8400)$ & $<0.001$ \\
\hline Serum creatinine, $\mu \mathrm{mol} / /$ & $84(74-95)$ & $82(74-93)$ & $83(72-94)$ & $84(73-97)$ & 0.94 \\
\hline \multicolumn{6}{|l|}{ Medical history } \\
\hline Coexistent atrial flutter & $36(18)$ & $35(20)$ & $30(18)$ & $29(17)$ & 0.68 \\
\hline Hypertension & $93(47)$ & $84(50)$ & $90(54)$ & $117(69)$ & $<0.001$ \\
\hline Diabetes & $13(7)$ & $10(6)$ & $12(7)$ & $20(12)$ & 0.07 \\
\hline Stroke & $20(10)$ & $9(5)$ & $10(6)$ & $15(9)$ & 0.64 \\
\hline Heart failure & $11(6)$ & $11(7)$ & $16(10)$ & $26(15)$ & 0.001 \\
\hline Myocardial infarction & $9(5)$ & $8(5)$ & $8(5)$ & $13(8)$ & 0.23 \\
\hline History of amiodarone treatment & & & & & $<0.001$ \\
\hline Current & $30(15)$ & $25(15)$ & $29(17)$ & $37(22)$ & \\
\hline Previous use & $24(12)$ & $29(17)$ & $30(18)$ & $40(23)$ & \\
\hline Never use & $147(73)$ & $117(68)$ & $108(65)$ & $95(55)$ & \\
\hline
\end{tabular}

Data are presented as means \pm standard deviations or medians (interquartile range), and counts (percentages)

$P$ values compares quartiles of CRP levels

Abbreviations: $L A D$ left atrial diameter, $L V E F$ left ventricular ejection fraction, WBC white blood cell count

$31,32]$. These inflammatory features may contribute to electrical and structural remodeling in atrial tissue and, thus, may promote recurrence of AF [33]. In support of this observation, previous studies have reported a potential association between elevated CRP levels and AF recurrence after catheter ablation [34, 35]. However, these mainly retrospective studies were small, had short follow-up duration, and used different cut-off levels for CRP. One retrospective cohort study involving a small and highly-selected sample of patients with AF used a cut-off value for abnormally high CRP of $5 \mathrm{mg} / \mathrm{l}$, a value which was selected based on the laboratory assay used in

Table 2 Incidence of recurrent AF after catheter ablation according to CRP quartiles

\begin{tabular}{lllll}
\hline Variable & CRP level & & & Quartile 4 \\
\cline { 2 - 5 } & Quartile 1 & Quartile 2 & Quartile 3 & Quand \\
\hline Quartile value, mg/l & $<0.8$ & $0.8-1.4$ & $1.5-2.7$ & $>2.7$ \\
Events/Patients & $60 / 201$ & $61 / 171$ & $55 / 167$ & $71 / 172$ \\
Incidence, $\%^{\mathrm{a}}$ & 33.1 & 41.9 & 37.0 & 53.4 \\
$95 \% \mathrm{Cl}$ & $24.4-42.3$ & $32.1-54.7$ & $29.9-49.1$ & $41.6-68.5$ \\
\hline
\end{tabular}

$P$ value was calculated by trend test of survival function across quartiles 


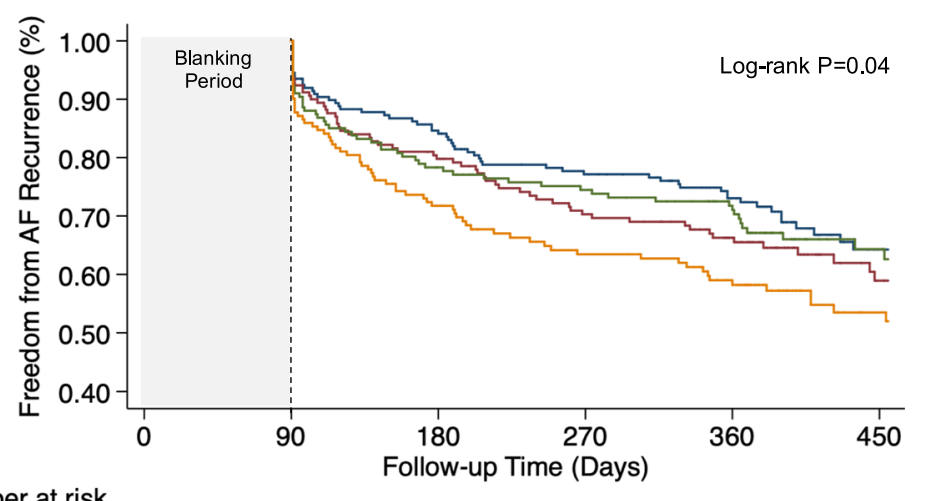

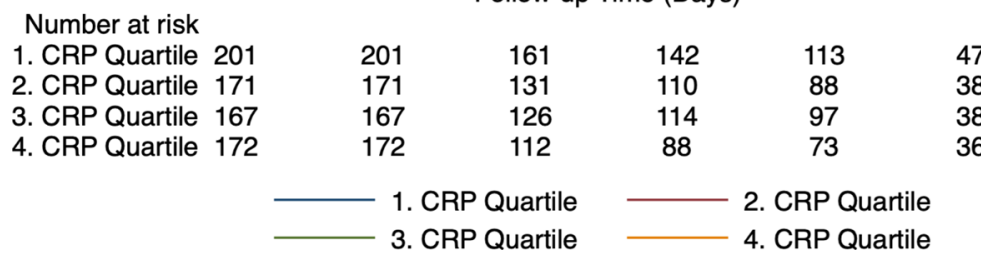

Fig. 1 Kaplan-Meier curves for AF recurrence across quartiles of CRP levels

the hospital [36]. Our study included significantly more patients with long-term observation and used a wellknown CRP cut-off value for cardiovascular risk stratification, which allowed us to validate and confirm the findings from previous studies. We have now found a consistent association of CRP with AF recurrence in a large sample of well-characterized AF patients, which significantly contribute to the knowledge in the interrelationship between subclinical inflammation and $\mathrm{AF}$ recurrence after ablation.

Assessment of inflammatory biomarkers other than CRP may help to better understand the potential association between inflammation and recurrence of $\mathrm{AF}$ after catheter ablation. In smaller studies elevated levels of interleukin-2 (IL-2) and interleukin-6 (IL-6) were found to be significantly associated with recurrent AF after ablation $[37,38]$. Another study showed that a IL-6 receptor genetic variant was associated with a higher risk of AF recurrence, emphasizing that the IL-6 pathway may affect the recurrence of AF [39]. Other markers of inflammation have been related to the risk of AF recurrence after catheter ablation, including matrix metalloproteinase- 2 and tumor necrosis factor- $\alpha$ [40]. Taken together, these findings suggest that chronic inflammation may have an arrhythmogenic effect and therefore could at least in part explain failure of catheter ablation.

Table 3 Hazard ratios for recurrent AF after catheter ablation according to CRP quartiles and continuous CRP levels

\begin{tabular}{|c|c|c|c|c|c|}
\hline \multirow[t]{2}{*}{ Variable } & \multicolumn{4}{|c|}{ CRP quartile } & \multirow{2}{*}{$\begin{array}{l}\text { Continuous } \\
\text { Per unit increase in log CRP }\end{array}$} \\
\hline & $1^{a}$ & 2 & 3 & 4 & \\
\hline Quartile value, mg/l & $<0.8$ & $0.8-1.4$ & $1.5-2.7$ & $>2.7$ & \\
\hline Hazard ratio unadjusted & 1.0 & 1.23 & 1.10 & 1.59 & 1.19 \\
\hline $95 \% \mathrm{Cl}$ & - & $0.86-1.76$ & $0.78-1.62$ & $1.13-2.25$ & $1.04-1.35$ \\
\hline$P$ value & - & 0.25 & 0.53 & 0.008 & 0.009 \\
\hline Hazard ratio adjusted for age and sex & 1.0 & 1.24 & 1.09 & 1.54 & 1.17 \\
\hline $95 \% \mathrm{Cl}$ & - & $0.87-1.77$ & $0.75-1.57$ & $1.09-2.18$ & $1.03-1.34$ \\
\hline$P$ value & - & 0.23 & 0.65 & 0.015 & 0.018 \\
\hline Hazard ratio adjusted for age and sex + additional factors & 1.0 & 1.26 & 1.15 & 1.60 & 1.21 \\
\hline $95 \% \mathrm{Cl}$ & - & $0.86-1.84$ & $0.78-1.70$ & $1.10-2.34$ & $1.05-1.39$ \\
\hline$P$ value & - & 0.24 & 0.48 & 0.014 & 0.009 \\
\hline
\end{tabular}

Models adjusted for additional factors controlled for body mass index, AF type (paroxysmal vs. persistent), history of hypertension (yes vs. no), history of heart failure (yes vs. no), history of obstructive sleep apnea (yes vs. no), duration of AF (years), and LAD Multivariable model included $n=659$ patients

${ }^{a}$ CRP Quartile 1 served as reference group for each comparison 
Table 4 Hazard ratios for recurrent AF after catheter ablation according to CRP cut-off value of $3 \mathrm{mg} / \mathrm{l}$

\begin{tabular}{|c|c|c|}
\hline \multirow[t]{2}{*}{ Variable } & \multicolumn{2}{|c|}{ CRP level, mg/l } \\
\hline & $<3^{a}$ & $\geq 3$ \\
\hline Events/Patients & $181 / 551$ & $66 / 160$ \\
\hline Incidence, \% ${ }^{b}$ & 36.9 & 53.8 \\
\hline $95 \% \mathrm{Cl}$ & $31.6-43.2$ & $41.6-69.6$ \\
\hline Hazard ratio unadjusted & 1.0 & 1.45 \\
\hline $95 \% \mathrm{Cl}$ & - & $1.09-1.92$ \\
\hline$P$ value & - & 0.010 \\
\hline Hazard ratio adjusted for age and sex & 1.0 & 1.41 \\
\hline $95 \% \mathrm{Cl}$ & - & $1.06-1.88$ \\
\hline$P$ value & - & 0.017 \\
\hline $\begin{array}{l}\text { Hazard ratio adjusted for age and } \\
\text { sex }+ \text { additional factors }\end{array}$ & 1.0 & 1.44 \\
\hline $95 \% \mathrm{Cl}$ & - & $1.06-1.95$ \\
\hline$P$ value & - & 0.019 \\
\hline
\end{tabular}

Models adjusted for additional factors controlled for body mass index, AF type (paroxysmal vs. persistent), history of hypertension (yes vs. no), history of heart failure (yes vs. no), history of obstructive sleep apnea (yes vs. no), duration of AF (years), and LAD

Multivariable model included $n=659$ patients

${ }^{a} \mathrm{CRP}$ group $<3 \mathrm{mg} / \mathrm{l}$ served as reference for each comparison

${ }^{\mathrm{b}}$ Incidence at 1 year of follow-up in percent

The findings of the current analysis may have several implications. First, given that failure rates of AF ablation remain significant, our results provide potential targets for therapeutic strategies to improve ablation success. Prospective epidemiologic studies demonstrated that obesity, smoking, high blood pressure and diabetes are independently associated with elevated levels of CRP and other inflammatory biomarkers [41-44]. This is in line with our observation showing that patients with higher CRP concentrations had a higher proportion of comorbid conditions, such as hypertension and higher body-mass index. Targeted therapies of those risk factors and lifestyle modifications have been shown to reduce CRP levels and improve maintenance of sinus rhythm in AF patients [45-47], suggesting that these interventions not only have an anti-inflammatory effect, but also reduce the burden of AF. Whether such risk factor and lifestyle interventions improve success rates of catheter ablation for AF by means of decreasing inflammation and thus CRP levels is currently unclear.

Second, previous trials have evaluated whether administration of anti-inflammatory therapy shortly after catheter ablation would reduce AF recurrence [48, 49]. Although the studies showed favorable results with regard to AF recurrence rates with anti-inflammatory therapy, interpretation of the findings is limited mainly by the small sample of participants, the short follow-up duration and the administration of different types of anti-inflammatory agents. Moreover, these studies did not specifically target patients with elevated CRP levels prior to ablation. Thus, there remains an unmet need for a large randomized controlled trial to evaluate the risks and benefits of anti-inflammatory therapy after ablation in AF patients. At least one ongoing trial is addressing this issue (IMPROVE-PVI ClinicalTrials.gov number, NCT04160117). From a mechanistic point of view, the association between pre-interventional subclinical inflammation and AF recurrence requires further investigations into the underlying biologic mechanism.

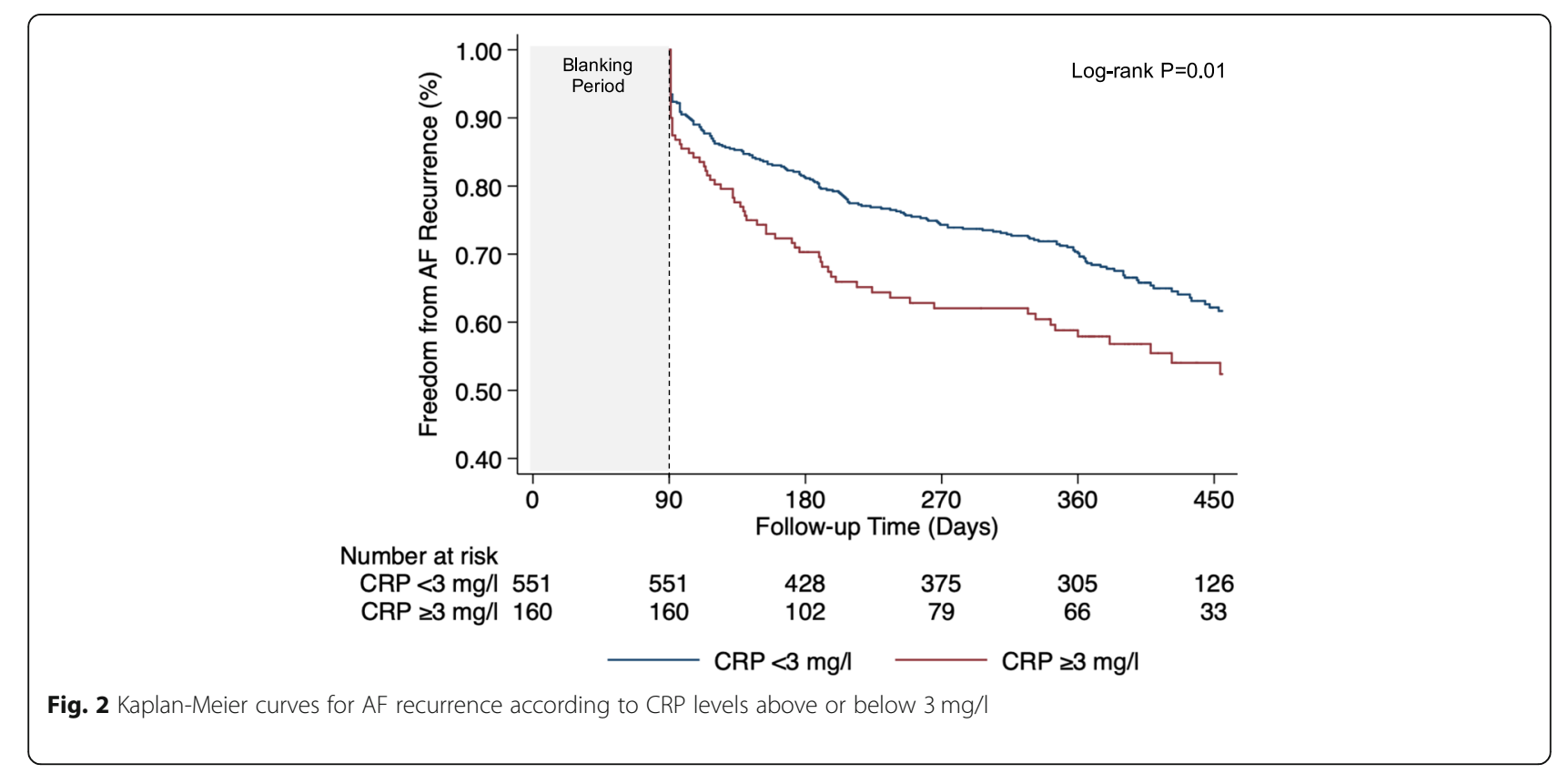




\section{Strengths and limitations}

The strength of this study is the prospective design including a large sample of well-characterized AF patients. Furthermore, the large number of confirmed events, the availability of many covariates and the low rate of missing values allowed us to perform meaningful analyses. Nonetheless, this study has some potential limitations that require discussion. First, patient recruitment started in 2011 and ablation techniques may have changed over time, which could have impacted procedural success rates. Second, we measured CRP only at baseline and thus, could not evaluate the effects of changes in levels over time, or the effect of postinterventional CRP levels. Such measures may have provided a better overview about subclinical inflammatory state of the patients included in this study. Third, the study sample included patients who were recruited at a Swiss study center and the generalizability of the results to other populations is unclear. Forth, more than $10 \%$ of patients who had undergone initial catheter ablation were lost to followup (Figure S1 in the Supplement) and did not have an ECG recording regarding their rhythm status which could have affected the results. Lastly, follow-up screening for AF was performed at 3, 6, and 12 months using predefined methods. It is possible however that AF recurrence events may have been missed.

\section{Conclusions}

Our data demonstrate that increasing CRP levels measured prior to catheter ablation were associated with a higher risk of AF recurrence. These findings support the hypothesis that inflammation may be involved in the recurrence of $\mathrm{AF}$ after catheter ablation.

\section{Supplementary information}

Supplementary information accompanies this paper at https://doi.org/10. 1186/s12872-020-01711-x.

Additional file 1: Figure S1. Flow diagram of patient selection and follow-up.

\section{Abbreviations}

AF: Atrial fibrillation; aHR: Adjusted hazard ratio; Cl: Confidence interval; CRP: C-reactive protein; LAD: Left atrial diameter; LVEF: Left ventricular ejection fraction

\section{Acknowledgements}

Not applicable.

\section{Authors' contributions}

PM, SK: Conceptualization, Methodology; PM, SA, SB, GV, AM: Data curation, Investigation; PM: Formal analysis; CS, DC, SO, MK: Funding acquisition; PM: Software; SK: Supervision; FS, SK: Validation; PM: Visualization; PM: Roles/ Writing - original draft; CS, FS, SA, SB, GV, AM, DC, SO, MK: Writing - review \& editing. The author(s) read and approved the final manuscript.

\section{Funding}

The SWISS-AF PVI study was supported by a grant of the Swiss National Science Foundation (PPOOP3_159322) and the Foundation for Cardiovascular
Research Basel (FCVR Basel). Dr. Conen has a McMaster University Department of Medicine Mid-Career Research Award; his work is supported by the Hamilton Health Sciences RFA Strategic Initiative Program.

\section{Availability of data and materials}

The datasets generated and analysed during the current study are not publicly available because the patient consent forms, as approved by the responsible ethics committee, do not allow the data to be made publicly available, but are available from the corresponding author on reasonable request.

Ethics approval and consent to participate

The study protocol was approved by the local ethics committee (Ethikkommission Nordwest- und Zentralschweiz). Written informed consent was obtained from all participants.

Consent for publication

Not applicable.

\section{Competing interests}

Christian Sticherling has received speaker honoraria from Biosense Webster and Medtronic and research grants from Biosense Webster, Daiichi-Sankyo, and Medtronic. David Conen has received consultant/speaker fees from Servier, Canada. Michael Kühne has received grants from Bayer, Pfizer-BMS, the Swiss National Science Foundation, and the Swiss Heart Foundation; and lecture or consulting fees from Daiichi-Sankyo, Boehringer Ingelheim, Bayer, Pfizer-BMS, AstraZeneca, Sanofi, Novartis, Merck Sharp \& Dohme, Medtronic, Boston Scientific, St. Jude Medical, Biotronik, Sorin, Zoll, Biosense Webster, and Abbott. The remaining authors declare that they have no competing interests.

\section{Author details}

'Division of Cardiology, Department of Medicine, University Hospital Basel, Petersgraben 4, 4031 Basel, Switzerland. ${ }^{2}$ Cardiovascular Research Institute Basel, University Hospital Basel, Basel, Switzerland. ${ }^{3}$ Population Health Research Institute, McMaster University, Hamilton, Ontario, Canada.

Received: 7 May 2020 Accepted: 22 September 2020

Published online: 29 September 2020

\section{References}

1. Krijthe BP, Kunst A, Benjamin EJ, Lip GY, Franco OH, Hofman A, Witteman $J C$, Stricker BH, Heeringa J. Projections on the number of individuals with atrial fibrillation in the European Union, from 2000 to 2060. Eur Heart J. 2013;34(35):2746-51.

2. Wolf PA, Benjamin EJ, Belanger AJ, Kannel WB, Levy D, D'Agostino RB. Secular trends in the prevalence of atrial fibrillation: the Framingham study. Am Heart J. 1996:131(4):790-5.

3. Wolf PA, Abbott RD, Kannel WB. Atrial fibrillation as an independent risk factor for stroke: the Framingham study. Stroke. 1991;22(8):983-8.

4. Conen D, Chae CU, Glynn RJ, Tedrow UB, Everett BM, Buring JE, Albert CM. Risk of death and cardiovascular events in initially healthy women with new-onset atrial fibrillation. JAMA. 2011;305(20):2080-7.

5. Cosedis Nielsen J, Johannessen A, Raatikainen P, Hindricks G, Walfridsson $H$, Kongstad O, Pehrson S, Englund A, Hartikainen J, Mortensen LS, et al. Radiofrequency ablation as initial therapy in paroxysmal atrial fibrillation. $\mathrm{N}$ Engl J Med. 2012;367(17):1587-95.

6. Wazni OM, Marrouche NF, Martin DO, Verma A, Bhargava M, Saliba W, Bash D, Schweikert R, Brachmann J, Gunther J, et al. Radiofrequency ablation vs antiarrhythmic drugs as first-line treatment of symptomatic atrial fibrillation: a randomized trial. JAMA. 2005;293(21):2634-40.

7. January CT, Wann LS, Alpert JS, Calkins H, Cigarroa JE, Cleveland JC Jr, Conti $J B$, Ellinor PT, Ezekowitz MD, Field ME, et al. 2014 AHA/ACC/HRS guideline for the management of patients with atrial fibrillation: a report of the American College of Cardiology/American Heart Association task force on practice guidelines and the Heart Rhythm Society. J Am Coll Cardiol. 2014; 64(21):e1-76.

8. Oral H, Knight BP, Ozaydin M, Tada H, Chugh A, Hassan S, Scharf C, Lai SW, Greenstein R, Pelosi F Jr, et al. Clinical significance of early recurrences of atrial fibrillation after pulmonary vein isolation. J Am Coll Cardiol. 2002;40(1): $100-4$. 
9. Hussein AA, Saliba WI, Martin DO, Bhargava M, Sherman M, Magnelli-Reyes C, Chamsi-Pasha M, John S, Williams-Adrews M, Baranowski B, et al. Natura history and long-term outcomes of ablated atrial fibrillation. Circ Arrhythm Electrophysiol. 2011:4(3):271-8.

10. Gaztanaga L, Frankel DS, Kohari M, Kondapalli L, Zado ES, Marchlinski FE. Time to recurrence of atrial fibrillation influences outcome following catheter ablation. Heart Rhythm. 2013;10(1):2-9.

11. Guo Y, Lip GY, Apostolakis S. Inflammation in atrial fibrillation. J Am Coll Cardiol. 2012;60(22):2263-70

12. Frustaci A, Chimenti C, Bellocci F, Morgante E, Russo MA, Maseri A. Histological substrate of atrial biopsies in patients with lone atrial fibrillation. Circulation. 1997;96(4):1180-4.

13. Conen D, Ridker PM, Everett BM, Tedrow UB, Rose L, Cook NR, Buring JE, Albert CM. A multimarker approach to assess the influence of inflammation on the incidence of atrial fibrillation in women. Eur Heart J. 2010;31(14): 1730-6

14. Aviles RJ, Martin DO, Apperson-Hansen C, Houghtaling PL, Rautaharju P, Kronmal RA, Tracy RP, Van Wagoner DR, Psaty BM, Lauer MS, et al. Inflammation as a risk factor for atrial fibrillation. Circulation. 2003;108(24): 3006-10.

15. Schnabel RB, Larson MG, Yamamoto JF, Sullivan LM, Pencina MJ, Meigs JB, Tofler GH, Selhub J, Jacques PF, Wolf PA, et al. Relations of biomarkers of distinct pathophysiological pathways and atrial fibrillation incidence in the community. Circulation. 2010;121(2):200-7.

16. Chung MK, Martin DO, Sprecher D, Wazni O, Kanderian A, Carnes CA, Bauer JA, Tchou PJ, Niebauer MJ, Natale A, et al. C-reactive protein elevation in patients with atrial arrhythmias: inflammatory mechanisms and persistence of atrial fibrillation. Circulation. 2001;104(24):2886-91.

17. Engelmann MD, Svendsen JH. Inflammation in the genesis and perpetuation of atrial fibrillation. Eur Heart J. 2005;26(20):2083-92.

18. Liu T, Li G, Li L, Korantzopoulos P. Association between C-reactive protein and recurrence of atrial fibrillation after successful electrical cardioversion: a meta-analysis. J Am Coll Cardiol. 2007;49(15):1642-8.

19. Fan J, Cao H, Su L, Ling Z, Liu Z, Lan X, Xu Y, Chen W, Yin Y. NT-proBNP, but not ANP and $C$-reactive protein, is predictive of paroxysmal atrial fibrillation in patients undergoing pulmonary vein isolation. J Interv Card Electrophysiol. 2012;33(1):93-100.

20. Lellouche N, Sacher F, Wright M, Nault I, Brottier J, Knecht S, Matsuo S, Lomas $\mathrm{O}$, Hocini M, Haissaguerre $\mathrm{M}$, et al. Usefulness of $\mathrm{C}$-reactive protein in predicting early and late recurrences after atrial fibrillation ablation. Europace. 2009;11(5):662-4.

21. Kornej J, Reinhardt C, Kosiuk J, Arya A, Hindricks G, Adams V, Husser D, Bollmann A. Response of high-sensitive C-reactive protein to catheter ablation of atrial fibrillation and its relation with rhythm outcome. PLoS One. 2012;7(8):e44165

22. Lin YJ, Tsao HM, Chang SL, Lo LW, Tuan TC, Hu YF, Udyavar AR, Tsai WC, Chang CJ, Tai CT, et al. Prognostic implications of the high-sensitive Creactive protein in the catheter ablation of atrial fibrillation. Am J Cardiol. 2010;105(4):495-501.

23. Kirchhof P, Benussi S, Kotecha D, Ahlsson A, Atar D, Casadei B, Castella M, Diener HC, Heidbuchel H, Hendriks J, et al. 2016 ESC guidelines for the management of atrial fibrillation developed in collaboration with EACTS. Eur Heart J. 2016:37(38):2893-962.

24. Goff DC Jr, Lloyd-Jones DM, Bennett G, Coady S, D'Agostino RB Sr, Gibbons R, Greenland P, Lackland DT, Levy D, O'Donnell CJ, et al. 2013 ACC/AHA guideline on the assessment of cardiovascular risk: a report of the American College of Cardiology/American Heart Association task force on practice guidelines. J Am Coll Cardiol. 2014;63(25 Pt B):2935-59.

25. Reiner Z, Catapano AL, De Backer G, Graham I, Taskinen MR, Wiklund O, Agewall S, Alegria E, Chapman MJ, Durrington P, et al. ESC/EAS guidelines for the management of dyslipidaemias: the task force for the management of dyslipidaemias of the European Society of Cardiology (ESC) and the European atherosclerosis society (EAS). Eur Heart J. 2011;32(14):1769-818.

26. Coelho Graça D, Golaz O, Magnin J-L, Fleurkens H, Rossier MF, Lescuyer P, Vuilleumier N. CRP-based cardiovascular risk assessment: new conventional CRP assay fit for purpose? J Appl Lab Med. 2018;2(6):952-9.

27. Calkins H, Hindricks G, Cappato R, Kim YH, Saad EB, Aguinaga L, Akar JG, Badhwar V, Brugada J, Camm J, et al. 2017 HRS/EHRA/ECAS/APHRS/ SOLAECE expert consensus statement on catheter and surgical ablation of atrial fibrillation. Heart Rhythm. 2017;14(10):e275-444.
28. Yeh ET, Willerson JT. Coming of age of C-reactive protein: using inflammation markers in cardiology. Circulation. 2003;107(3):370-1.

29. Ridker PM. Cardiology patient page. C-reactive protein: a simple test to help predict risk of heart attack and stroke. Circulation. 2003;108(12):e81-5.

30. Ridker PM. High-sensitivity C-reactive protein: potential adjunct for global risk assessment in the primary prevention of cardiovascular disease. Circulation. 2001;103(13):1813-8.

31. Chen MC, Chang JP, Liu WH, Yang CH, Chen YL, Tsai TH, Wang YH, Pan KL. Increased inflammatory cell infiltration in the atrial myocardium of patients with atrial fibrillation. Am J Cardiol. 2008;102(7):861-5.

32. Ito K, Date T, Ikegami M, Hongo K, Fujisaki M, Katoh D, Yoshino T, Anzawa R, Nagoshi T, Yamashita S, et al. An immunohistochemical analysis of tissue thrombin expression in the human atria. PLoS One. 2013;8(6):e65817.

33. McGarry TJ, Narayan SM. The anatomical basis of pulmonary vein reconnection after ablation for atrial fibrillation: wounds that never felt a scar? J Am Coll Cardiol. 2012;59(10):939-41.

34. Letsas KP, Weber R, Burkle G, Mihas CC, Minners J, Kalusche D, Arentz $T$. Pre-ablative predictors of atrial fibrillation recurrence following pulmonary vein isolation: the potential role of inflammation. Europace. 2009;11(2):158-63.

35. Liu J, Fang PH, Dibs S, Hou Y, Li XF, Zhang S. High-sensitivity C-reactive protein as a predictor of atrial fibrillation recurrence after primary circumferential pulmonary vein isolation. Pacing Clin Electrophysiol. 2011; 34(4):398-406

36. Sotomi Y, Inoue K, Ito N, Kimura R, Toyoshima Y, Masuda M, Iwakura K, Fujii $K$. Incidence and risk factors for very late recurrence of atrial fibrillation after radiofrequency catheter ablation. Europace. 2013;15(11):1581-6.

37. Cabrera-Bueno F, Medina-Palomo C, Ruiz-Salas A, Flores A, RodriguezLosada N, Barrera A, Jimenez-Navarro M, Alzueta J. Serum levels of interleukin-2 predict the recurrence of atrial fibrillation after pulmonary vein ablation. Cytokine. 2015;73(1):74-8.

38. Henningsen KM, Nilsson B, Bruunsgaard H, Chen X, Pedersen BK, Svendsen $J H$. Prognostic impact of hs-CRP and IL-6 in patients undergoing radiofrequency catheter ablation for atrial fibrillation. Scand Cardiovasc J. 2009:43(5):285-91.

39. Wu G, Cheng M, Huang $H$, Yang B, Jiang H, Huang C. A variant of IL6R is associated with the recurrence of atrial fibrillation after catheter ablation in a Chinese Han population. PLoS One. 2014;9(6):e99623.

40. Kimura T, Takatsuki S, Inagawa K, Katsumata $Y$, Nishiyama T, Nishiyama N, Fukumoto K, Aizawa Y, Tanimoto Y, Tanimoto K, et al. Serum inflammation markers predicting successful initial catheter ablation for atrial fibrillation. Heart Lung Circ. 2014;23(7):636-43.

41. Pradhan AD, Manson JE, Rifai N, Buring JE, Ridker PM. C-reactive protein, interleukin 6, and risk of developing type 2 diabetes mellitus. JAMA. 2001; 286(3):327-34.

42. Visser M, Bouter LM, McQuillan GM, Wener MH, Harris TB. Elevated Creactive protein levels in overweight and obese adults. JAMA. 1999;282(22): 2131-5.

43. Sesso HD, Buring JE, Rifai N, Blake GJ, Gaziano JM, Ridker PM. C-reactive protein and the risk of developing hypertension. JAMA. 2003;290(22):294551.

44. Wannamethee SG, Lowe GD, Shaper AG, Rumley A, Lennon L, Whincup PH. Associations between cigarette smoking, pipe/cigar smoking, and smoking cessation, and haemostatic and inflammatory markers for cardiovascular disease. Eur Heart J. 2005;26(17):1765-73.

45. Kasapis C, Thompson PD. The effects of physical activity on serum Creactive protein and inflammatory markers: a systematic review. J Am Coll Cardiol. 2005:45(10):1563-9.

46. Gallus S, Lugo A, Suatoni P, Taverna F, Bertocchi E, Boffi R, Marchiano A, Morelli D, Pastorino U. Effect of tobacco smoking cessation on C-reactive protein levels in a cohort of low-dose computed tomography screening participants. Sci Rep. 2018:8(1):12908.

47. Rienstra M, Hobbelt AH, Alings M, Tijssen JGP, Smit MD, Brugemann J, Geelhoed B, Tieleman RG, Hillege HL, Tukkie R, et al. Targeted therapy of underlying conditions improves sinus rhythm maintenance in patients with persistent atrial fibrillation: results of the RACE 3 trial. Eur Heart J. 2018; 39(32):2987-96

48. Deftereos S, Giannopoulos G, Kossyvakis C, Efremidis M, Panagopoulou V, Kaoukis A, Raisakis K, Bouras G, Angelidis C, Theodorakis A, et al. Colchicine for prevention of early atrial fibrillation recurrence after pulmonary vein 
isolation: a randomized controlled study. J Am Coll Cardiol. 2012;60(18): 1790-6.

49. Koyama T, Tada H, Sekiguchi Y, Arimoto T, Yamasaki H, Kuroki K, Machino T, Tajiri K, Zhu XD, Kanemoto-Igarashi M, et al. Prevention of atrial fibrillation recurrence with corticosteroids after radiofrequency catheter ablation: a randomized controlled trial. J Am Coll Cardiol. 2010;56(18):1463-72.

\section{Publisher's Note}

Springer Nature remains neutral with regard to jurisdictional claims in published maps and institutional affiliations.

Ready to submit your research? Choose BMC and benefit from:

- fast, convenient online submission

- thorough peer review by experienced researchers in your field

- rapid publication on acceptance

- support for research data, including large and complex data types

- gold Open Access which fosters wider collaboration and increased citations

- maximum visibility for your research: over $100 \mathrm{M}$ website views per year

At BMC, research is always in progress.

Learn more biomedcentral.com/submissions 